DOI 10.37882/2223-2974.2021.02.01

\title{
КОНЦЕПЦИЯ ПРИМЕНЕНИЯ МЕЖДИСЦИПЛИНАРНОГО ПОДХОДА К РЕАЛИЗАЦИИ ПРОЕКТОВ ПО ФОРМИРОВАНИЮ КОМФОРТНОЙ СРЕДЫ ЖИЗНИ ЧЕЛОВЕКА В УСЛОВИЯХ ЦИФРОВОЙ ЭКОНОМИКИ'
}

\section{THE CONCEPT OF APPLICATION \\ OF THE INTERDISCIPLINARY APPROACH \\ TO THE IMPLEMENTATION \\ OF PROJECTS FOR THE FORMATION \\ OF A COMFORTABLE ENVIRONMENT \\ OF HUMAN LIFE IN THE CONDITIONS \\ OF THE DIGITAL ECONOMY}

\section{T. Ablyazov}

Summary: The implementation of projects to create a comfortable environment for human life in the digital economy is associated with the interaction of specialists from various fields of knowledge, which necessitates the development of a concept for the application of an interdisciplinary approach in the implementation of such projects. The article substantiates the relevance of developing a scientifically grounded concept for the application of an interdisciplinary approach to the implementation of projects to create a comfortable environment for human life; measures to improve the mechanism of interdisciplinary interaction based on the creation of a service integrator that ensures the functioning of a digital platform in the field of urban development are proposed; a system of principles for the interaction of project participants to create a comfortable living environment is proposed, and barriers that impede the effective implementation of projects for the development of territories in the digital economy are identified.

Keywords: comfort of human life environment, digital economy, interdisciplinary approach, digital platform.

\author{
Аблязов Тимур Хасанович \\ К.э.н, доцент, Санкт-Петербургский государственный \\ архитектурно-строительный университет \\ 3234969@mail.ru
}

Аннотация: Реализация проектов по формированию комфортной среды жизни человека в условиях цифровой экономики сопряжена с взаимодействием специалистов различных областей знаний, что обуславливает потребность разработки концепции применения междисциплинарного подхода в рамках реализации подобных проектов. В статье обоснована актуальность разработки научной концепции применения междисциплинарного подхода к реализации проектов по формированию комфортной среды жизни человека; предложены меры по усовершенствованию механизма междисциплинарного взаимодействия на основе создания сервисного интегратора, обеспечивающего функционирование цифровой платформы в области городского развития; предложена система принципов взаимодействия участников проектов по формированию комфортной среды жизни, а также определены барьеры, препятствующие эффективной реализации проектов по развитию территорий в цифровой экономике.

Ключевые слова: комфортность среды жизни человека, цифровая экономика, междисциплинарный подход, цифровая платформа.
$\mathrm{B}$ словиях становления цифровой экономики современные технологии внедряются во все аспекты жизнедеятельности населения, что находит отражение в трансформации подходов к пониманию комфортности среды жизни человека. Городская среда должна соответствовать требованиям безопасности, экологичности, жизнеспособности, многофункциональности и экономической эффективности [1]. Переход к шестому технологическому укладу предполагает обеспечение вышеуказанных требований на основе распространения цифровых технологий. Ускорение развития техноло- гий и потребность в одновременном обеспечении всех требований к комфортности среды жизни обуславливают потребность в применении междисциплинарного подхода в целях обеспечения проектов по формированию комфортной среды жизни человека всеми необходимыми данными и решениями для максимально полного удовлетворения нужд населения.

Важность совместных усилий специалистов различных областей знаний признается профессиональным сообществом. Так, вопросы комфортности среды жизни

Статья подготовлена в рамках работы по Гранту Президента Российской Федерации МК-462.2020.6. 
человека всё чаще рассматриваются на пересечении социально-культурной, экологической и экономических сфер [2]. За рубежом междисциплинарное взаимодействие ученых, властей и предпринимателей для развития территорий уже применяется на практике, о чем свидетельствует проект Smart Nation, реализуемый в Сингапуре $[3,4]$. Кроме того, даже жители территории становятся участниками междисциплинарного взаимодействия посредством распространения практики вовлечения жителей в проекты развития среды жизни [5].

В настоящее время также получает распространение концепция "умного города», которая основана на постепенном внедрении цифровых технологий в среду жизни, причем спектр направлений совершенствования широк - жилищно-коммунальное хозяйство, здравоохранение, образование, государственное управление и пр. [6]. Наряду с «умным городом» существует концепция «зеленой инфраструктуры», подразумевающей обеспечение комфортности среды жизни на основе повышения уровня озелененности территории [7], что однако исключает из рассмотрения множество других аспектов функционирования территории.

В условиях цифровой экономики комфортность среды жизни человека рассматривается учеными с экологической (качество жизни, безопасность, продолжительность жизни), социальной (кластеризация среды, создание условий для цифровой экономики) и урбанистической (разнообразие элементов среды, удобство их расположения, удовлетворение потребностей общества) точек зрения [8]. Городское пространство исследуется как многоуровневая целостная система, характеризуемая взаимодействием составляющих её элементов [9]. В целом, признается тот факт, что в условиях цифровой экономики важен не столько объем собираемой информации, который с учетом стремительного распространения технологий велик, сколько возможности безопасного хранения, передачи и комплексного анализа данных различными группами специалистов [10].

Таким образом, существующие научные взгляды не отражают весь комплекс взаимосвязей, возникающих при реализации проектов по развитию территорий в условиях цифровой экономики. Необходима разработка научно обоснованной концепции применения междисциплинарного подхода к реализации проектов по формированию комфортной среды жизни человека, описывающая взаимодействие всех субъектов и объектов данного процесса.

Целью разработки и применения данной концепции выступает определение основных подходов к взаимодействию участников проектов по формированию комфортной среды жизни человека в условиях цифровой экономики. Для достижения поставленной цели необходимо решение следующих задач:
1. Совершенствование механизма междисциплинарного взаимодействия в рамках проектов по формированию комфортной среды жизни человека в условиях цифровой экономики. На современном этапе развития технологий одним из ключевых направлений цифровизации процессов функционирования территории выступают цифровые платформы, представляющие огромный потенциал для решения социально-экономических задач в области здравоохранения, образования, транспорта, безопасности среды жизни и других сфер жизнедеятельности населения [11].

Управление цифровыми платформами как многоуровневыми системами сбора и аналитики данных может быть обеспечено посредством формирования сервисного интегратора - организации, обладающей набором компетенций в области создания и поддержания функциональности цифровых платформ на всех этапах их жизненного цикла (от фазы запуска, на которой важно определить ликвидность и уровень доверия к платформе, до фазы зрелости, на которой необходимо непрерывно внедрять новейшие технологические решения В целях обеспечения конкурентоспособности данной системы [12]). Сервисный интегратор в области сбора данных о функционировании территории позволит централизованно агрегировать информацию и выступит аналитической базой для реализации проектов по формированию комфортной среды жизни человека на основе применения междисциплинарного подхода.

Одним из примеров формирования сервисного интегратора в области городского развития выступает The Dublin Dashboard, в рамках которого данные собираются как в онлайн-режиме (показатели, характеризующие состояние окружающей среды и транспортной системы), так и с определенной периодичностью (социально-экономические показатели) [13].

Формирование подобной цифровой платформы должно быть основано на государственной поддержке, выраженной в создании нормативно-правовой базы функционирования данной системы и установлении этапов её внедрения в различных регионах страны (после успешного применения в рамках пилотных проектов). Финансирование цифровой платформы должно быть возможно на принципах государственно-частного партнерства (ГЧП), что, с одной стороны, позволит реализовать масштабный проект за счет частных инвестиций, а с другой стороны, даст возможность коммерческим организациям выгодно внедрить свои технологические решения, так как ГЧП подразумевает долгосрочность сотрудничества и гарантированность спроса на предлагаемые услуги [14, 15].

Сервисный интегратор станет основой для получения коммерческими организациями, занимающимися развитием территорий, актуальной информации о по- 
требностях населения в тех или иных товарах и услугах, а также особенностях поведения людей, что позволит им адаптировать свои проекты под спрос населения, тем самым одновременно получив собственную выгоду и повысив комфортность городской среды. С точки зрения научных исследований подобная цифровая платформа станет статистической базой для проведения междисциплинарных исследований и выработки дальнейших путей совершенствования среды жизни человека.

2. Формирование системы приниипов взаимодействия участников проектов по повышению комфортности среды жизни человека в условиях цифровой экономики. Применение междисциплинарного подхода должно осуществляться с учетом следующих принципов:

- объективность агрегируемых и используемых данных, что может быть достигнуто путем сбора и анализа информации посредством цифровых инструментов, значительно снижающих субъективный фактор;

- доступность и открытость данных для всех участников междисциплинарного взаимодействия, так как предлагаемая концепция основана на одновременном решении поставленных задач по развитию среды жизни множеством участников проекта, что невозможно при отсутствии доступа к информации у отдельных субъектов междисциплинарного взаимодействия;

- сопоставимость данных по различным территориям, что обеспечит возможность проведения сравнительного анализа проектов по формированию комфортной среды жизни человека в целях определения их эффективности и нахождения путей совершенствования принимаемых решений еще на этапе подготовки проекта;

- централизация сбора данных в целях осуществления контроля за полнотой сбора информации, а также обеспечения высокой доступности данных для участников междисциплинарного взаимодействия, которым не придется самостоятельно агрегировать разрозненные данные;

- обеспечение баланса интересов участников междисциплинарного взаимодействия и установление границ их ответственности за результаты проекта, что позволит реализовывать проект, основываясь на четко определенных правах и обязанностях каждого участника.

3. Определение барьеров, затрудняющих реализачию проектов по формированию комфортной среды жизни человека в условиях цифровой экономики. В настоящее время междисциплинарное взаимодействие при реализации подобных проектов в условиях цифровой экономики еще только начинает активно применяться, что обусловлено негативным воздействием следующих барьеров [16, 17]:

- отсутствие открытого доступа к данным о функци- онировании территории, а также разобщенность массивов информации между различными ведомствами даже в рамках одной территории;

- отраслевая направленность процесса сбора данных, что затрудняет применение междисциплинарного подхода;

- отсутствие понимания целесообразности сбора данных для их последующего междисциплинарного анализа;

- нехватка компетенций у кадрового состава органов статистики и государственных ведомств для работы с наиболее современными цифровыми инструментами;

- нормативно-правовая база применения междисциплинарного подхода при реализации проектов по формированию комфортной среды жизни человека на основе цифровых технологий находится на начальном этапе своего развития, что затрудняет полномасштабное внедрение всех преимуществ предлагаемой концепции;

- нехватка инфраструктуры для развертывания цифровых платформ междисциплинарного взаимодействия, так как в большинстве случаев данный подход понимается специалистами как автоматизация существующих процессов, а не как применение кардинально нового подхода к решению поставленных задач на основе цифровых технологий;

- недостаточный уровень локализации данных, то есть их представление без учета пространственного наложения на конкретные области анализируемой территории;

- отсутствие единообразных стандартов сбора данных, что не позволяет проводить всесторонний анализ информации о развитии территории;

- уровни цифровизации различных направлений жизнедеятельности территории отличны, что затрудняет выработку единого стандарта сбора данных и, как следствие, применение междисциплинарного подхода.

В заключение стоит сказать, что предлагаемая в данной работе концепция применения междисциплинарного подхода к реализации проектов по формированию комфортной среды жизни человека в условиях цифровой экономики является основой для эффективного взаимодействия всех участников проекта в целях достижения ключевой цели развития территорий - повышения её комфортности для населения страны. Предложенный механизм междисциплинарного взаимодействия на основе создания сервисного интегратора, а также система принципов междисциплинарного взаимодействия позволят решить существующие проблемы, сопутствующие реализации проектов по формированию комфортной среды жизни человека в условиях цифровой экономики. 


\section{ЛИТЕРАТУРА}

1. Б Боброва Д.С., Спиридонов Н.С. Общественные пространства как место социокультурного взаимодействия // Современные общественные пространства как инструмент развития городской среды: материалы межрегион. науч.-практ. конф. 29-30 ноября 2018 года: СПбГАСУ. - СПб., 2018. С. 73-77.

2. Корендясева Е.В. Создание устойчивой городской среды как основы экологического благополучия москвичей // Вестник университета Правительства Москвы. 2017. № 4. С. 15-19.

3. Осипова М.Г. Инновационная модель Республики Сингапур // Юго-восточная Азия: актуальные проблемы развития. 2018. Т. 1. № 2 (39). С.173-182.

4. Василенко И.А. «Сингапурское чудо» в фокусе политического анализа: искушение и разочарование в азиатской хай-тек-утопии // Власть. 2018. C. 169-175.

5. Ц Центр городских компетенций ACИ. Атлас успешных практик соучастия и вовлечения жителей в развитие городской cреды. URL: https://100gorodov.ru/ atlas (дата обращения: 15.11.2020).

6. Vishnivetskaya A., Alexandrova E. «Smart city» concept. Implementation practice // IOP Conference Series: Materials Science and Engineering. 2019. Vol. 497, 012019. URL: https://doi.org/10.1088/1757-899X/497/1/012019 (дата обращения: 04.12.2020).

7. Подойницына Д.С. Критический анализ концепции "зеленая инфраструктура" // AMIT. 2016. №1 (34). URL: https://marhi.ru/AMIT/2016/1kvart16/pod/pod. pdf (дата обращения: 06.12.2020).

8. Угрюмова А. А., Паутова Л. Е., Паутова Е. П. Комфортность как фактор устойчивого развития городской среды // Россия: тенденции и перспективы развития. 2018. №13-2. С. 245-251.

9. Шилехина М.С. Культурное пространство современного города как объект междисциплинарного исследования // Культура и образование: научно-информационный журнал вузов культуры и искусств. 2017. №2 (25). С. 39-46.

10. Аблязов Т.Х., Асаул В.В., Вишнивецкая А.И. Формирование комфортной среды жизни человека на основе концепции "программируемого" города // Московский экономический журнал. 2020. №8. С. 149-159.

11. Ablyazov T., Rapgof V. Digital platforms as the basis of a new ecological system of socioeconomic development // IOP Conference Series: Material Science and Engineering, vol. 497, 012002, 2019. URL: doi:10.1088/1757-899X/497/1/012002 (дата обращения: 01.11.2020).

12. Месропян В. Цифровые платформы - новая рыночная власть. 2018. URL: https://www.econ.msu.ru/sys/raw.php?0=46781\&p=attachment (дата 0бpaщения: 25.11.2020).

13. McArdle G., Kitchin R. The Dublin Dashboard: design and development of a real-time analytical urban dashboard // ISPRS Annals of the Photogrammetry, Remote Sensing and Spatial Information Sciences. 2016. Volume III-4/W1. P. $19-25$.

14. Белоусова 0.Ю., Мокин С.В., Огородова У.С., Орехович А.В. ГЧП в ІТ: новые возможности // P\&P Unity и ФРИИ. 2018. 40 c. URL: http://ppunity.ru/files/ files/\%D0\%93\%D0\%A7\%D0\%9F\%20\%D0\%B2\%20IT.pdf (дата обращения: 17.09.2020).

15. Крыканов Д.Д., Патрунина К.А. Управление рисками применения инструментов государственно-частного партнерства для цифровых инфраструктурных проектов // Управление риском и безопасность. 2018. № 4. С. 47-55.

16. Короткова Е., Мокрушина К., Куричева Е., Журавлев С., Ирбитская И. Управление пространственно-экономическим развитием города: скрытые ресурсы // Московский урбанистический форум. 2016. 192 c. URL: https://mosurbanforum.ru/upload/iblock/79a/79a888088ede868386d868faef5efa0f.pdf (дата 06ращения: 10.11.2020).

17. Грибанов Ю.И. Цифровизация национальной экономики: вызовы и ответственность бизнеса (государственно-частное партнерство) // Динамика взаимоотношений различных областей науки в современных условиях: сб. ст. по матер. междунар. науч.-практ. конф. В 3 ч. Ч. 1. Стерлитамак: АМИ, 2018.

C. $42-50$

(с) Аблязов Тимур Хасанович (3234969@mail.ru).

Журнал «Современная наука: актуальные проблемы теории и практики» 